\title{
Kinematic Analysis of Handwriting Movements in Patients with Alzheimer's Disease, Mild Cognitive Impairment, Depression and Healthy Subjects
}

\author{
A. Schröter R. Mergl K. Bürger H. Hampel H.-J. Möller U. Hegerl \\ Department of Psychiatry, Ludwig Maximilian University Munich, Munich, Germany
}

\section{Key Words}

Alzheimer's disease - Mild cognitive impairment . Depression · Kinematic handwriting analysis · Digitizing graphic tablet . Automation - Mini Mental State Examination

\begin{abstract}
A variety of studies have demonstrated that motor disorders, parkinsonism and extrapyramidal motor symptoms (EPMS) are common in patients with Alzheimer's disease (AD). Several studies have reported an association of EPMS with severity, progression and poor prognosis of AD. The majority of these studies used clinical assessments for the rating of EPMS. In this study, kinematic handwriting analysis was used to quantify differences in fine hand motor function in patients with probable $A D$ and mild cognitive impairment $(\mathrm{MCl}$, as an assumed initial stage of AD) compared to depressed patients and healthy controls. Both patients with $\mathrm{MCl}$ and patients with probable AD exhibited loss of fine motor performance. Movements of AD patients were significantly less regular than those of healthy controls.
\end{abstract}

Copyright $\odot 2003$ S. Karger AG, Basel

\section{Introduction}

Since Western society is facing the perspective of a growing elderly population with increasing numbers of patients with Alzheimer's disease (AD), improvement in the diagnosis of very early and, if possible, preclinical phases of $\mathrm{AD}$ is required. Since no single marker of $\mathrm{AD}$ exists, the diagnosis of dementia, AD and other diseases leading to dementia (for instance Lewy body dementia, LBD) is a decision based on multiple sources of information that are considered simultaneously.

The dominant feature of $\mathrm{AD}$ is the progressive decline of cognition, especially mnestic functions and orientation. Though impaired cognitive functions can be observed even in preclinical stages of $\mathrm{AD}$ [1], age-related impairments in mnestic functions can be observed in all subjects of this age group [2-4].

Hence other indicators for the detection of people who are at high risk for developing AD are necessary. In this context, the assessment of motor functions has become of increasing interest for mainly three reasons: (1) for the early diagnosis of $\mathrm{AD},(2)$ as a possible predictor of the progression of the disease and (3) for the diagnostic differentiation between $\mathrm{AD}$ and other forms of dementia, e.g. LBD.

Neurological symptoms are no diagnostic criteria for the diagnosis of $\mathrm{AD}$, but starting with the first report of

Dipl.-Psych. Andreas Schröter

Psychiatrische Klinik und Poliklinik der Ludwig-Maximilians-Universität München Nussbaumstrasse 7, D-80336 München (Germany)

Tel. +49 8951605866, Fax +498951605875

E-Mail schroete@nk-i.med.uni-muenchen.de
Fax + 41613061234 E-Mail karger@karger.ch www.karger.com
Accessible online at: www. karger.com/dem 
Pearce in 1974 [5], who found extrapyramidal features of parkinsonian type in 40 out of 65 patients, growing attention has been paid to the role of extrapyramidal signs and other motor dysfunction in the course of $\mathrm{AD}$ [6]. A variety of studies have demonstrated that parkinsonism and extrapyramidal motor symptoms (EPMS) are common in patients with $\mathrm{AD}$, the reported prevalence of EPMS ranges between 6 and 92\% [7-11]. Motor dysfunction occurs even in mildly demented AD patients without EPMS [12]. EPMS seem to be apparent already in initial stages of $\mathrm{AD}$, and several studies have reported an association between EPMS and AD severity, progression, functional decline, poor prognosis and mortality [13-19].

The existence of EPMS in AD patients gained importance in view of the discussion of LBD and the Lewy body variant of $\mathrm{AD}$ [20]. While a number of studies reported a higher incidence of parkinsonism and EPMS and a faster cognitive decline in these patients [21-24], other studies found no specific clinical symptoms [25-27].

The majority of these studies used clinical examinations or standardized clinical rating scales, like the Abnormal Involuntary Movement Scale or the Unified Parkinson's Disease Rating Scale, to examine the presence of EPMS. Standardized neuropsychological tests were used to assess severity and nature of cognitive and psychomotor dysfunction like aphasia, apraxia, agnosia and executive function disorders [28].

Only few studies applied quantitative instrumental methods to measure EPMS [29-35]. Instrumental measurement has two methodological advantages compared with rating scales: (1) instrumental tests allow an objective and repeatable measurement of symptoms and may even reveal subtle and subclinical motor abnormalities that are below the threshold of clinical detection. In rating scales, the registration of symptoms depends on the clinical impression of the rater. Therefore the reliability, especially in longitudinal and multicenter studies, depends on good interrater and intrarater reliability, respectively. Richards et al. [36] reported problems with the recognition and conformity of mild and subclinical subtle symptoms. (2) Instrumental tests allow a linear measurement of the severity of symptoms on a continuous interval scale. In rating scales, the registration of symptoms and therefore the statistical analysis of data is restricted to a discontinuous nominal or ordinal scale.

Another approach for the measurement and analysis of motor dysfunction is the quantification of kinematic handwriting movements using a digitizing tablet [37]. Besides the measurement of velocity and acceleration, this method allows exact statements on the quality or automation and accuracy of handwriting movements. Kinematic handwriting analysis has been proven to be a valid method to detect even subtle motor abnormalities in several studies with schizophrenic patients [38, 39] and patients with obsessive-compulsive disorder [40]. Kinematics of handwriting has also be shown to be a valid measure of dysfunction of the extrapyramidal system. It reflects motor abnormalities in patients with Parkinson's disease (PD) in a very sensitive way, especially bradykinesia [41] and micrographia [42]; similarly, subclinical disturbances of the extrapyramidal system in patients with other basal ganglia disease (e.g. Huntington's disease) could be exactly measured using kinematic handwriting analysis [43]. Slavin et al. [34] used a similar method in a comparative analysis of handwriting movements in $\mathrm{AD}$ patients, Huntington's disease and PD patients, and healthy controls (HCs).

In the present study, kinematic handwriting analysis was used to compare quantified fine hand motor function in patients with probable $\mathrm{AD}$ and mild cognitive impairment (MCI, as an assumed initial stage of AD) with that of patients with the diagnosis of a major depression (DEPs) and HCs. Major depression represents a relevant differential diagnosis of AD. Moreover, extrapyramidal disturbances (especially psychomotor retardation resembling that in patients with PD) could also be objectified in patients with depression [44], and several studies suggest that basal ganglia dysfunction represents a relevant factor in the pathophysiology of depression [45]. Sabbe et al. [46] could demonstrate that psychomotor retardation in depression (suggesting basal ganglia dysfunction) has a cognitive component, since motor differences between depressed patients and healthy controls increase with task complexity. Therefore it will be interesting to address the question whether $\mathrm{AD}$ patients can be differentiated from elderly DEPs by using kinematic handwriting parameters.

Above all, the main aim of this study was to examine whether the kinematic analysis of hand-motor dysfunction in even subclinical intensity can be used to differentiate between $\mathrm{AD}, \mathrm{MCI}$ and depression in the elderly. On the basis of the literature cited above we formulated the following hypotheses:

(1) AD and MCI patients exhibit a lower degree of automation and regularity of handwriting movements than DEPs and HCs.

(2) The severity of motor symptoms in AD patients is correlated with lower automation and regularity of handwriting movements. 
Table 1. Clinical characteristics of patients and controls

Table 2. Summary of writing habits

\begin{tabular}{llllll}
\hline & AD & MCI & DEP & HC & $\mathrm{p}$ \\
\hline Participants & 35 & 39 & 39 & 40 & \\
Gender (f/m) & $17 / 18$ & $23 / 16$ & $30 / 9$ & $23 / 17$ & n.s. \\
Age, years & $70.6 \pm 11.2$ & $60.6 \pm 11,1$ & $60.2 \pm 8.7$ & $65.6 \pm 7.9$ & 0.000 \\
MMSE score & $21.3 \pm 2.9$ & $27.8 \pm 1.7$ & $27.2 \pm 2.2$ & $29.3 \pm 0.7$ & 0.000 \\
Severity of dementia & & & & & 0.000 \\
$\quad$ MMSE 15-17 & 6 & - & - & - & \\
$\quad$ MMSE 18-22 & 16 & - & 2 & - & \\
$\quad$ MMSE 23-30 & 13 & 39 & 37 & 40 & \\
\hline
\end{tabular}

Age and MMSE scores are means \pm SD

\begin{tabular}{llllll}
\hline & AD & MCI & DEP & HC & $\mathrm{p}$ \\
\hline Edinburgh score & $84.1 \pm 30.4$ & $90.3 \pm 30.8$ & $83.7 \pm 33.7$ & $88.4 \pm 30.7$ & n.s. \\
Writing hand (r/l) & $35 /-$ & $38 / 1$ & $39 /-$ & $40 /-$ & n.s. \\
Frequency of writing/day & & & & & 0.011 \\
$\quad<10 \mathrm{~min} /$ day & 29 & 23 & 28 & 23 & \\
$10-20 \mathrm{~min} /$ day & 1 & 1 & 3 & 8 & \\
$>20 \mathrm{~min} /$ day & 5 & 15 & 8 & 9 & \\
\hline
\end{tabular}

Edinburgh scores are means $\pm \mathrm{SD}$, all other scores reflect actual numbers.

\section{Materials and Methods}

\section{Patients and Controls}

A sample was selected from all patients $(n=173)$ admitted to the outpatient clinic for memory disorders ('Gedächtnissprechstunde') at the Department of Psychiatry of the Ludwig Maximilians University, Munich, on the basis of the following criteria:

- diagnosis of probable AD according to the NINCDS-ADRDA criteria for dementia [47],

- diagnosis of MCI according to the criteria for MCI of Petersen et al [48] and

- diagnosis of major depression according to DSM-III-R criteria [49].

We excluded all patients with a history or current clinical evidence of a stroke or any other additional organic condition that could adversely affect cognition or motor function. Cognitive function was examined using the 'Mini Mental State Examination' (MMSE) [50]. Only patients with mild or moderate cognitive disturbances (MMSE score above 15) were included in the study.

Since the literature suggests that there is a higher risk for older patients to develop acute and subacute extrapyramidal side effects under neuroleptic treatment even with very low doses [51, 52], patients with neuroleptic or lithium treatment were excluded from further analysis. Psychotropic medication included antidepressants (tricyclic and tetracyclic antidepressants, TTA, and selective seroton- in re-uptake inhibitors, SSRI), nootropics and acetylcholinesterase inhibitors.

After a complete description of the study, written informed consent was obtained from all participants. Kinematic analysis of handwriting movements, using a digitizing tablet, a questionnaire on writing habits and the 'Edinburgh Handedness Inventory' (EHI) [53], were obtained from 35 patients with probable AD, 39 patients with the diagnosis of MCI and 21 patients with a diagnosis of depression. Additionally, 18 elderly medicated depressive inpatients and 40 elderly healthy controls with an age above 55 years were examined.

The clinical characteristics of the patients and controls are shown in table 1. Summaries of the writing habits and of medications currently prescribed for all participants are shown in tables 2 and 3.

\section{Apparatus}

Handwriting movements were recorded using a commercial WACOM-IV digitizing tablet and a pressure-sensitive stylus. All participants wrote with the inking stylus on a paper fastened to the digitizing tablet. The $x-y$-coordinates of the stylus tip position on the digitizing tablet were recorded with a sampling rate of maximal $200 \mathrm{~Hz}$ and a spatial resolution of $0.05 \mathrm{~mm}$, and concurrently transmitted to a personal computer interface. 
Table 3. Summary of medications currently prescribed

\begin{tabular}{lcccc}
\hline & AD & MCI & DEP & HC \\
\hline $\begin{array}{l}\text { No medication } \\
\text { Psychotropic medication }\end{array}$ & 16 & 31 & 13 & 32 \\
$\quad$ Antidepressants & 3 & 1 & 13 & - \\
$\quad$ SSRI & 3 & 1 & 4 & - \\
$\quad$ Tri-/tetracyclic & - & - & 9 & - \\
$\quad$ Nootropics & 6 & 2 & 2 & - \\
$\quad \begin{array}{l}\text { Combination of antidepressants } \\
\quad \text { and nootropics }\end{array}$ & 2 & - & 1 & - \\
$\quad$ Benzodiazepine & - & 1 & - & - \\
Other medication & 8 & 4 & 10 & 8 \\
\hline
\end{tabular}

\section{Tasks and Procedure}

Participants were seated on a chair with the digitizing tablet placed on a desk in front of them. All participants were given the possibility to adjust the height of the chair and the position of the digitizing tablet. All participants were instructed to perform two movement tasks. Task 1 meant drawing concentric superimposed circles of $12 \mathrm{~mm}$ in diameter as fast and fluently as possible with their dominant hand for $30 \mathrm{~s}$; task 2 asked the participants to draw concentric superimposed circles of $12 \mathrm{~mm}$ in diameter as fast and fluently as possible with their dominant hand while simultaneously performing an additional distraction task (pressing a counting device as often as possible) with the nondominant hand for $10 \mathrm{~s}$.

Both tasks were initially demonstrated to the participants. Afterwards all participants were given the opportunity to practice until they were familiar with the procedure. If necessary, patients were reminded of the task or were given additional demonstrations.

\section{Kinematic Handwriting Analysis}

Subsequent standardized kinematic handwriting analysis of the y-coordinate's writing movements was performed with the software 'CS 4.3' [54]. The program segments handwriting motions into half circles (called 'strokes') corresponding to the vertical up and down movements. A stroke is defined by two sequential extrema of maximum or minimum curvature. These transition points correspond to changes in direction and therefore to a minimum velocity of 0 . Automated hand movements are characterized by single peaked, bellshaped velocity profiles of the strokes.

With CS 4.3 the mean peak velocity (V, the arithmetical mean of the velocity peaks of all strokes) and V-SD (the standard deviation of the intraindividual velocity profile) were calculated. The writing frequency (Freq), i.e. the number of strokes per second, was also calculated.

Non-parametric kernel estimates [37] were used to calculate a parameter for the automation of the movement $(\mathrm{NCV}=$ number of changes of direction of velocity), a parameter of the smoothness of the handwriting movement. As mentioned above, automation for a single stroke is assumed to go along with an ideal NCV value of 1 . In figure 1, the concept of segmentation and automation is demonstrated by an example of an AD patient (female, 72 years old, $\mathrm{NCV}=$ $5.41)$ and a matched healthy control $(\mathrm{NCV}=1.27)$.
Furthermore, the relative velocity (V-Rel), as a measure of the proportion of the intraindividual (V-SD) to the individual peak velocity $(\mathrm{V})$, was calculated by dividing the mean peak velocity $\mathrm{V}$ by its standard deviation V-SD.

Frequency and NCV are indicators of the automation of movement, while both V-SD and V-Rel are indicators of the coordination and regularity of movement sequences.

\section{Statistical Design and Methods}

All data were entered into a SPSS database for statistical analysis. Comparisons of frequency data between patient groups were done using $\chi^{2}$ analyses. Between-group differences of age were explored using one-way analyses of variance (ANOVA), between-group differences of the lateralization quotient of the EHI as well as the MMSE score by use of Kruskal-Wallis tests. Spearman-Brown correlation coefficients for all groups were calculated to explore possible relationships between handwriting parameters, age and MMSE scores, since some of these variables (MMSE scores, NCV, V-SD, V-Rel) were not normally distributed (Kolmogorov-Smirnov test: $p \leq 0.05$ ). Otherwise, in the case of normal distribution, Pearson's correlation coefficients were computed.

Due to reports of SSRI- and acetylcholinesterase inhibitorinduced extrapyramidal side effects [55-57], 3 medication groups were formed to rule out possible effects of psychotropic medication on kinematic handwriting performance (group 1: no medication, group 2: psychotropic medication (antidepressants and/or nootropics) and group 3: other medication). Due to the significant correlation between age and kinematic parameters, kinematic parameters were submitted as dependent variables to a $4 \times 3$ univariate analyses of covariance (ANCOVA, Bonferroni adjusted) design with 'diagnosis' (AD, MCI, major depression, $\mathrm{HC}$ ) and 'medication' as betweengroup factors controlled for 'age' as the covariate. Significant F statistics were explored using post hoc ANCOVA. Despite the fact that variances were unequal (Levene tests: $p \leq 0.05$ ), the dependent variables were not transformed to homogenize variance because sample sizes were at least $n=35$ and almost equal $(35 \leq n \leq 40)$, and because it is well known that ANOVA is quite robust regarding heterogeneity of variances if the compared groups are large enough (at least $\mathrm{n}=10$ ) and if sample sizes are almost equal [58]. All hypothesis tests were two-sided and statistical significance was set at $\mathrm{p} \leq 0.05$.

\section{Results}

\section{Sociodemographic and Clinical Characteristics and Writing Habits}

The one-way ANOVA revealed a significant effect of age $(\mathrm{F}=9.714 ; \mathrm{p}=0.000)$ and MMSE scores $\left(\chi^{2}=94.73\right.$; $\mathrm{p}=0.000)$. Post hoc Scheffé tests displayed no significant differences in age between MCI patients, DEPs and HCs, while $\mathrm{AD}$ patients were significantly older than DEPs $(\mathrm{p}=$ $0.000)$ and MCI patients $(\mathrm{p}=0.000)$. A $\chi^{2}$ analysis for gender showed no significant differences between all groups (compare table 1). An analysis of the medications currently prescribed showed that AD patients and DEPs consumed significantly more medication, especially psychotropic medication like antidepressants and/or nootro- 


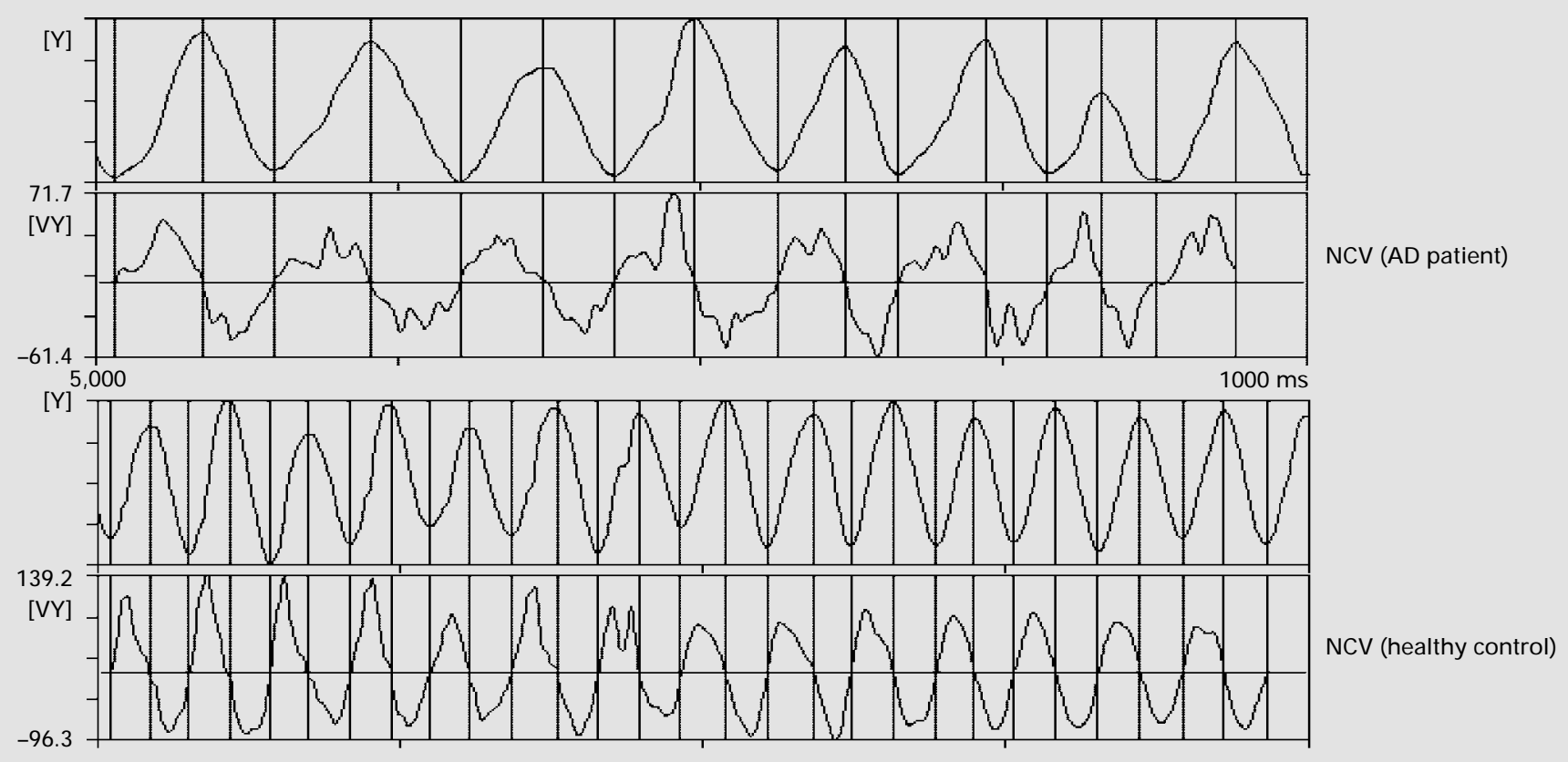

Fig. 1. The concept of segmentation and automation: velocity and acceleration curves necessary to circles are segmented into basal motor units (strokes). Based on this segmentation, kinematic parameters can be computed, e.g. the NCV. Higher NCV values represent disturbances of handwriting automation. The ideal NCV score is 1 . The graph illustrates disturbances of hand drawing automation $(\mathrm{NCV}=5.41)$ in an AD patient, compared with an $\mathrm{HC}$ with a high degree of hand movement automation ( $\mathrm{NCV}=1.27)$; both probands are female and 72 years old.

pics, than MCI patients and HCs $\left(\chi^{2}=41.11 ; \mathrm{p}=0.000\right.$ table 3). All participants but 1 were right-handed. There were no group differences for the lateralization quotient of the EHI $\left(\chi^{2}=5.70 ; p=0.13\right)$. Results regarding the frequency of handwriting per day (3 categories: under $10 \mathrm{~min} /$ day, $10-20 \mathrm{~min} /$ day, more than $20 \mathrm{~min} /$ day) showed that especially AD patients wrote less than the other groups $\left(\chi^{2}=16.502 ; \mathrm{p}=0.011\right.$; table 2$)$.

\section{Differences in Kinematic Handwriting Parameters \\ between Patients and Healthy Controls}

Univariate ANCOVA revealed significant effects of age (for task 1: Freq, $\mathrm{F}=11.227 ; \mathrm{p}=0.001$; V-Rel, $\mathrm{F}=$ 13.969; $\mathrm{p} \leq 0.001$; for task 2: Freq, $\mathrm{F}=7.450 ; \mathrm{p}=0.007$; V-Rel, $\mathrm{F}=3.932 ; \mathrm{p}=0.049$; counting device, $\mathrm{F}=15.591$; $\mathrm{p} \leq 0.001$ ) and diagnosis (see below) on kinematic handwriting parameters in both task 1 and task 2 . There was no significant effect of medication or interaction between diagnosis and medication.
Results of ANOVA for task 1 showed significant group effects for velocity variation (V-SD, $\mathrm{F}=4.072 ; \mathrm{p}=0.008$ ) and relative velocity (V-Rel, $F=3.132 ; p=0.028)$. Frequency, automation (NCV) and $\mathrm{V}$ did not significantly differ between the four groups, peak velocity was even slightly elevated in AD patients compared to healthy controls. Post hoc ANCOVA revealed that both the individual V-SD and the V-Rel were significantly increased in $A D$ patients compared to healthy controls $(\mathrm{p}=0.004, \mathrm{p}=$ 0.048; respectively). In addition, $\mathrm{AD}$ patients drew the circles with significantly higher V-SD than depressed patients $(\mathrm{p}=0.033)$ and patients with MCI $(\mathrm{p}=0.042)$. Depressed patients were found to exhibit significantly higher V-SD than did healthy subjects $(\mathrm{p}=0.005)$.

ANOVA of the kinematic parameters for task 2 presented similar results. There were significant group effects for V-Rel $(F=5.768 ; p=0.001)$ and NCV $(F=3.011 ; p=$ 0.032 ). Again there was no significant difference in writing frequency, $\mathrm{V}$ and the intraindividual V-SD between 
Table 4. Summary of task 1

\begin{tabular}{lcccc}
\hline & AD & MCI & DEP & HC \\
\hline Frequency, Hz & $2.59 \pm 1.24$ & $2.40 \pm 1.35$ & $3.05 \pm 1.23$ & $2.97 \pm 1.02$ \\
NCV & $4.00 \pm 4.81$ & $4.09 \pm 4.46$ & $2.64 \pm 3.93$ & $1.83 \pm 1.10$ \\
V, mm/s & $118.63 \pm 82.26$ & $101.63 \pm 52.31$ & $114.28 \pm 49.38$ & $102.38 \pm 34.74$ \\
V-SD, mm/s & $23.68 \pm 14.77$ & $16.44 \pm 9.76$ & $17.38 \pm 7.26$ & $15.21 \pm 7.62$ \\
V-Rel, \% & $22.08 \pm 11.92$ & $17.08 \pm 6.64$ & $16.08 \pm 5.60$ & $14.71 \pm 4.22$
\end{tabular}

Data are means $\pm \mathrm{SD}$.

Table 5. Summary of task 2

\begin{tabular}{lcccc}
\hline & AD & MCI & DEP & HC \\
\hline Frequency, Hz & $2.73 \pm 1.35$ & $2.62 \pm 1.45$ & $3.10 \pm 1.22$ & $3.41 \pm 0.90$ \\
NCV & $3.54 \pm 4.54$ & $3.37 \pm 3.34$ & $2.21 \pm 2.27$ & $1.41 \pm 0.63$ \\
V, mm/s & $113.21 \pm 59.91$ & $112.54 \pm 63.90$ & $114.42 \pm 44.46$ & $115.38 \pm 31.56$ \\
V-SD, mm/s & $25.78 \pm 15.63$ & $19.7 \pm 13.83$ & $21.06 \pm 11.20$ & $19.05 \pm 7.62$ \\
V-Rel, \% & $24.37 \pm 13.59$ & $18.58 \pm 9.65$ & $18.23 \pm 6.51$ & $16.56 \pm 5.35$ \\
Counting device & $21.97 \pm 10.57$ & $26.97 \pm 11.80$ & $27.31 \pm 11.61$ & $32.35 \pm 7.68$ \\
\hline
\end{tabular}

Data are means \pm SD.

the four groups. There was also a significant effect for the distraction task $(\mathrm{F}=2.777 ; \mathrm{p}=0.044)$. Post hoc ANCOVA revealed that the V-Rel in AD patients was significantly higher compared with all other groups (MCI $\mathrm{p}=$ 0.033; DEP $\mathrm{p}=0.043 ; \mathrm{HC} \mathrm{p} \leq 0.001)$. Moreover, AD and MCI patients drew circles with significantly higher NCV than HCs ( $p=0.024, p=0.021$; respectively). As to operating the counting device, HCs achieved a significantly higher performance than AD patients $(p=0.012)$, DEPs $(p=0.038)$ and MCI patients $(p=0.020)$. Summaries of the results of both tasks are presented in table 4,5 .

\section{Associations between the Severity of Cognitive Decline} and Kinematic Handwriting Parameters

Kolmogorov-Smirnov tests revealed that MMSE scores, NCV, V-SD and V-Rel were not normally distributed. Thus Pearson correlation coefficients were calculated to explore possible associations between Freq, V and age. Spearman-Brown correlation was calculated in order to detect possible associations between kinematic parameters and MMSE scores. Analogously, this type of correlation was used in order to explore associations between $\mathrm{NCV}, \mathrm{V}-\mathrm{SD}, \mathrm{V}-\mathrm{Rel}$ and age.
Cognitive function was negatively correlated with age (Spearman's $\rho=-0.129 ; p=0.112$ ). In both tasks, age was significantly correlated with frequency (task $1: \mathrm{r}=-0.247$, $\mathrm{p}=0.002 ;$ task 2: $\mathrm{r}=-0.209, \mathrm{p}=0.01)$ and V-Rel (task 1: Spearman's $\rho=0.285, \mathrm{p}=0.000$; task 2: Spearman's $\rho=$ $0.173, p=0.035$ ). Moreover, higher age was found to be significantly associated with higher NCV for drawing circles without distraction (Spearman's $\rho=0.226, p=$ 0.005).

Significant correlations were found in both tasks between cognitive function and kinematic handwriting parameters, reflecting poorer motor coordination in cognitively impaired patients (fig. 2-5). Significant negative correlations were found between MMSE score and NCV (task 2: Spearman's $\rho=-0.190, \mathrm{p}=0.02$ ), V-SD (task 1: Spearman's $\rho=0.223, p=0.006$ ) and V-Rel (task 1: Spearman's $\rho=-0.226, p=0.005$; task 2: Spearman's $\rho=$ $-0.210 ; p=0.01)$. Higher writing frequency, indicating better automation, was significantly correlated with a higher MMSE score in task $2(\mathrm{r}=0.170, \mathrm{p}=0.038)$. Peak velocity was not significantly correlated with MMSE scores and age. 

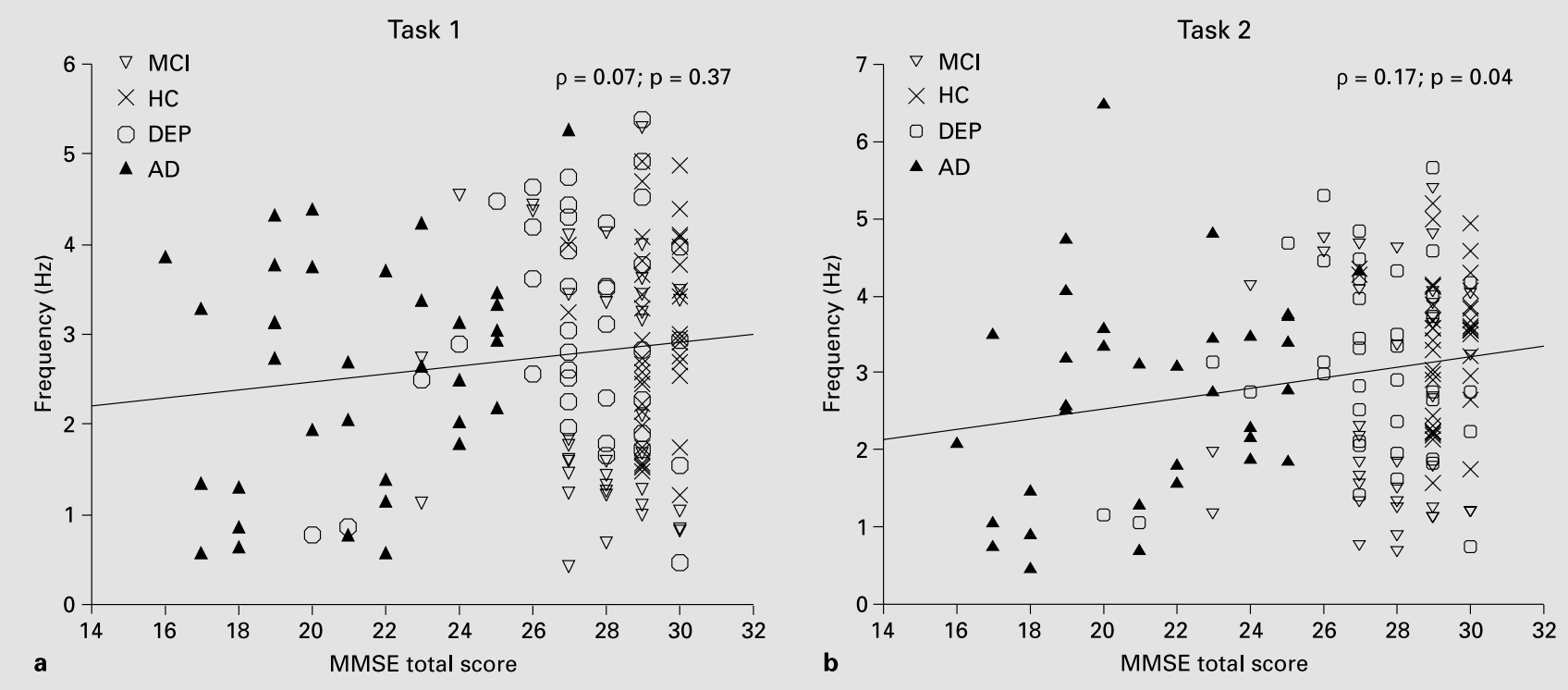

Fig. 2. Scatterplots showing associations between frequency (mean number of half-circles drawn with the dominant hand per second) under two task conditions (a without simultaneous pressing of a counting device with the nondominant hand; $\mathbf{b}$ with simultaneous pressing of this device) and total MMSE scores in 35 patients with probable AD, 39 patients with MCI, 39 DEPs and 40 HCs.

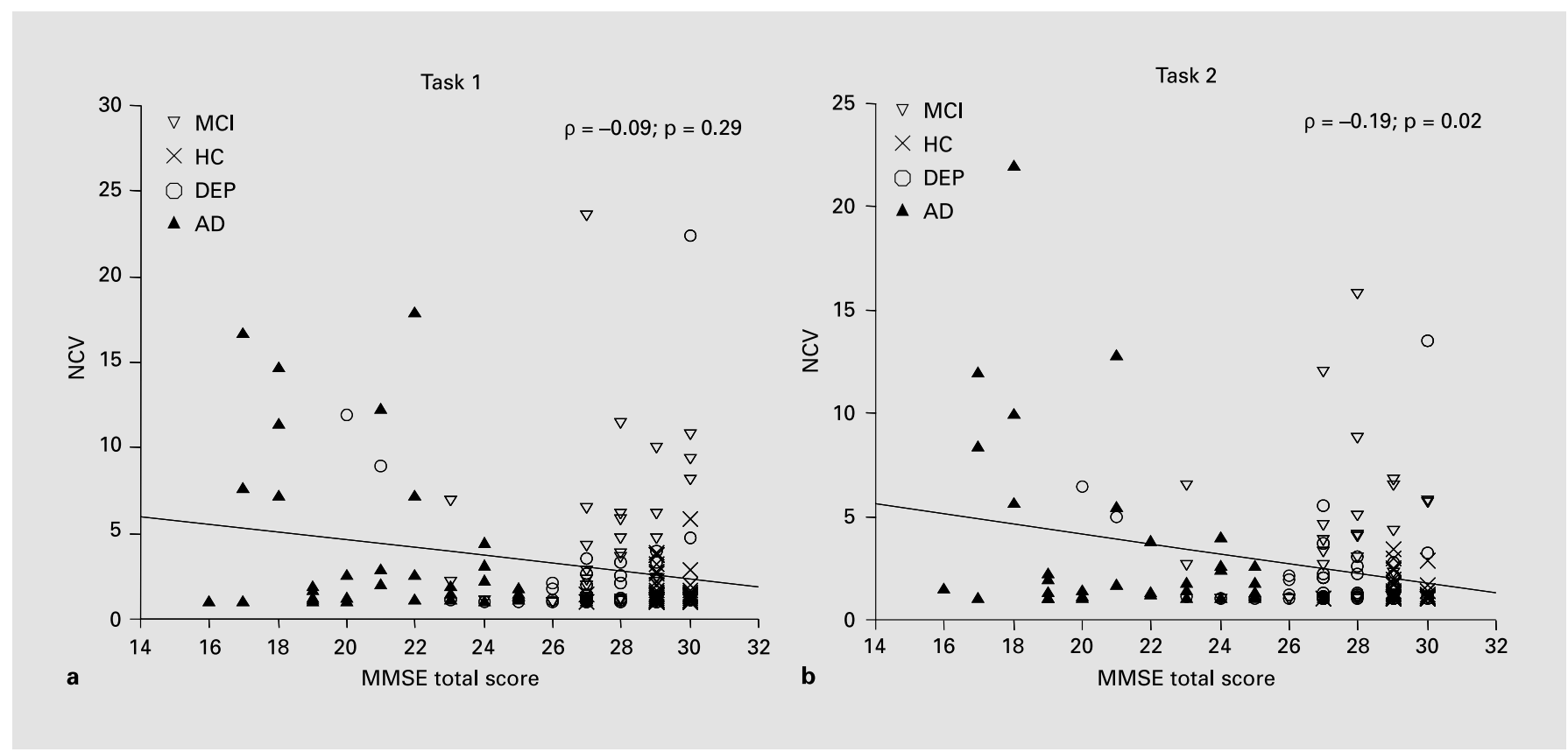

Fig. 3. Scatterplots showing associations between NCV (mean number of changes of direction of velocity per stroke for fast drawing of superimposed concentric circles with the dominant hand) and MMSE scores in the same patients and under the same conditions elaborated in figure 2. 

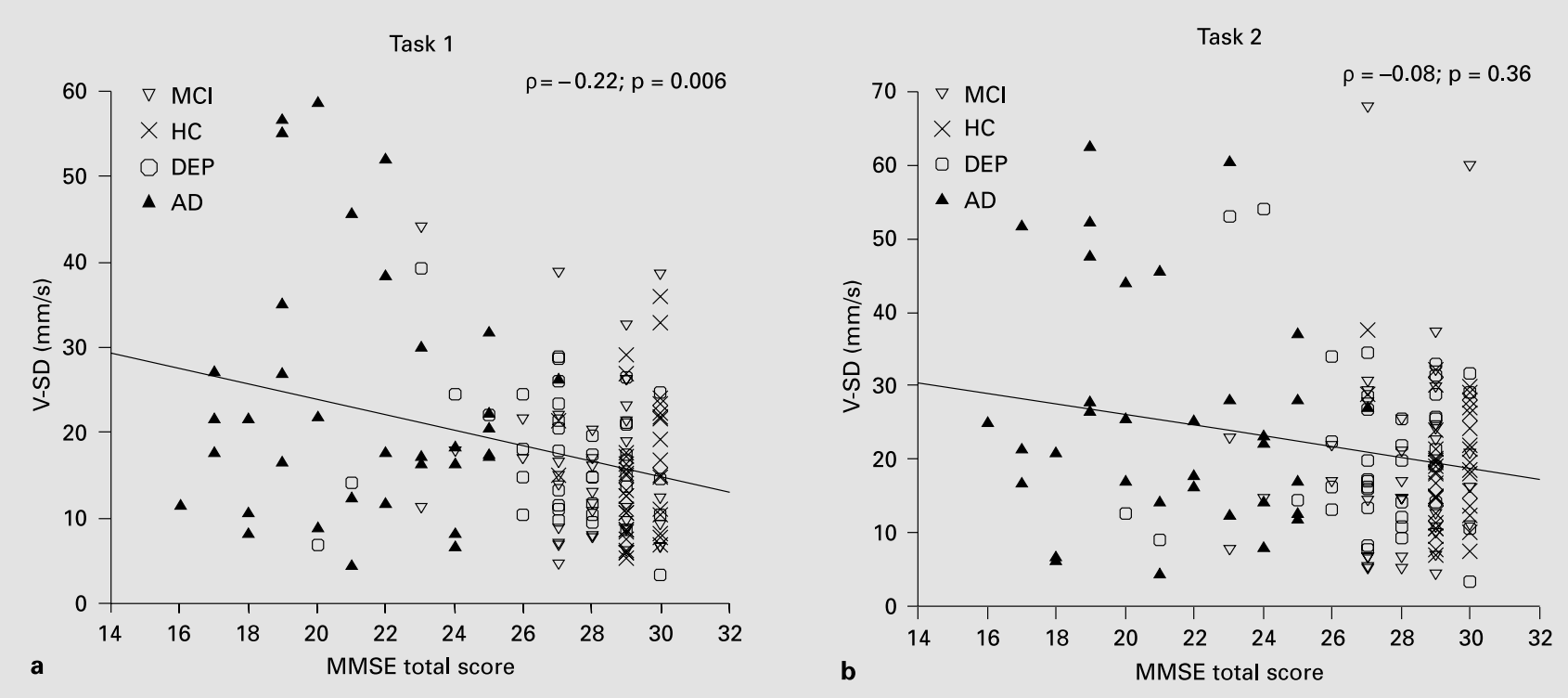

Fig. 4. Scatterplots showing associations between V-SD (standard deviation of the intraindividual velocity profile for fast drawing of superimposed concentric circles with the dominant hand) and MMSE scores in the same patients and under the same conditions elaborated in figure 2.
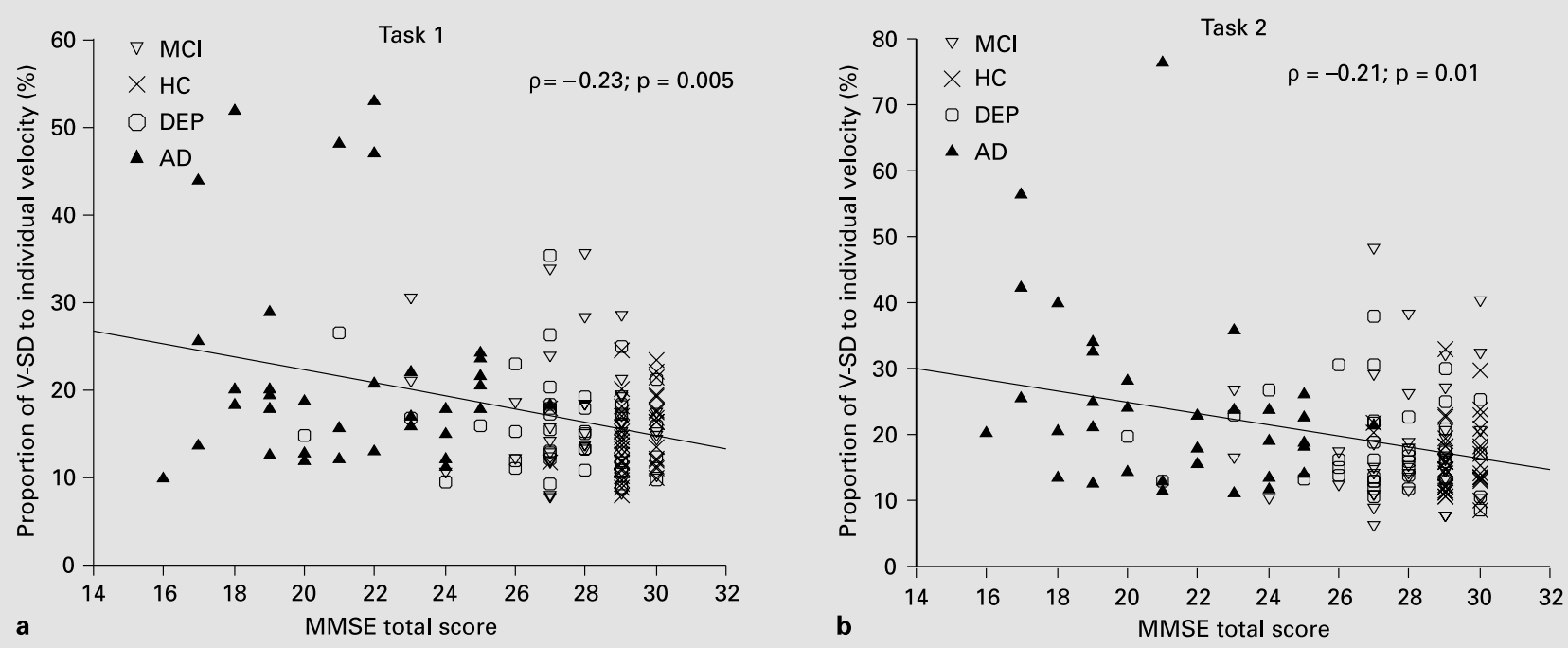

Fig. 5. Scatterplots showing associations between V-Rel (measure of the proportion of the intraindividual V-SD to the individual peak velocity for fast drawing of superimposed concentric circles with the dominant hand) and MMSE scores in the same patients and under the same conditions elaborated in figure 2. 


\section{Discussion}

The results of the present study demonstrate that quantitative kinematic handwriting parameters are related to cognitive status in elderly patients. Patients with MCI and patients with probable AD exhibited a loss of fine motor performance. Especially when compared to HCs, movements of AD patients were significantly less automated, accurate and regular. These group differences in kinematic handwriting parameters persisted even after statistically controlling for age and medication.

Differentiation between patients with $\mathrm{MCI}$ and healthy subjects increased with task complexity in task 2 . This underlines the findings of Kluger et al. [31], who administered a comprehensive motor test battery, including computer-based tests, to mild $\mathrm{AD}$ and MCI patients. Compared to healthy controls, MCI patients performed worse on tasks involving fine and complex motor function, while $\mathrm{AD}$ patients also exhibited motor dysfunction even on tasks assessing gross motor control.

Medication had no effect on kinematic handwriting performance in this study. However, the absence of a medication effect should be interpreted with caution as the lack of significance could be a reflection of the small sample size, and hence the statistic may have been underpowered. The strong effect of age is in line with findings of other groups. Morgan et al. [59] reported on an age effect upon abductive and adductive movements in a kinematic analysis, with older healthy subjects exhibiting more asymmetries and lower peak velocities than younger healthy subjects. Bellgrove et al. [60] could demonstrate that older adults produced slower and less efficient movements. Using the same paradigm as in the present study, Mergl et al. [61] showed an effect of age upon kinematic handwriting parameters in healthy subjects, with younger subjects exhibiting higher peak velocities and a higher degree of automation than older subjects.

Although we found a significant age effect, the differences in kinematic handwriting parameters cannot be explained merely on the basis of age, since MCI patients exhibited poorer motor performance compared to healthy subjects without a significant difference in age between these groups.

It is possible that other conditions interfered with the loss of fine motor performance in the patient groups, e.g. PD. Hand movements and the generation of writing movements are complex processes involving the integration of different instances, from planning to the activation and execution of simple motor programs [62, 63]. Disturbances in any of these instances therefore result in dis- turbed movement sequences. Yet motor skills, expressed by mean peak velocity, were still intact in all participants, indicating that the differences in fine motor performance are an expression of concurrent cognitive impairment.

Since cognitive impairments, culminating in dementia and depression, are among the most frequent and disabling conditions in the elderly, there exists a high degree of comorbidity between them. Reports on the prevalence of depression in AD patients vary [64, 65]. Fichter et al. [66] described an excess of comorbidity between cognitive impairment and depression in very old people (aged 85 years and above). Schröder et al. [67] found that in MCI patients complaints of cognitive deficits were significantly correlated with higher scores on depression. Steffens et al. [68] reported an association of cognitive impairment with depression severity among older patients with unipolar major depression. Significant correlations between cognitive impairment, depression and neuropsychologic test performance could be detected [2,69]. Particularly the clinically important differentiation between MCI, as an assumed initial stage of dementia, and depression is aggravated in elder patients. As MCI may accompany psychomotor retardation in depression in older patients and vice versa, it might have affected kinematic handwriting parameters in both groups to a similar extent. This may have prevented a striking discrimination between both MCI and DEP groups and AD patients. Depression severity should be further addressed in future studies controlled by the use of depression rating scales.

The concept of MCI describes cognitive deficits that exceed normal physiological aging processes, but do not fulfill the criteria for dementia. Longitudinal follow-up studies showed a progressive decline from MCI to clinically probable AD up to a rate of $15 \%$ per year [70-72]. Depression also seems to be associated with an increased risk of incident dementia [73]. Therefore further longitudinal evaluation of the clinical course and kinematic handwriting parameters of patients with $\mathrm{MCI}$ and depression, including other types of dementia, e.g. LBD, is required to appraise the predictive value of kinematic handwriting analysis.

Longitudinal studies of hand-motor dysfunction in $\mathrm{AD}$ patients will be clinically relevant because in order to make therapeutic decisions it is important to know whether AD patients with motor disorders in an early stage of disease have a poorer prognosis and a faster cognitive decline than $\mathrm{AD}$ patients without these early signs of motor dysfunction.

It is concluded that quantitative analysis of fine motor functions is a useful tool for dementia research and looks 
promising for the important differential diagnosis between $\mathrm{AD}, \mathrm{MCI}$ and depression.

$\mathrm{AD}$ and MCI patients differ from healthy subjects in automation parameters and regularity of movement sequence.

$\mathrm{AD}$ and $\mathrm{MCI}$ patients reveal a typical fine motor pattern: a decrease in automation with an unchanged peak velocity.
Motor dysfunction quantified by kinematic handwriting analysis is significantly correlated to MMSE scores.

\section{Acknowledgments}

We thank all the patients and participants for their cooperation in this study. Special thanks are due to the staff of the outpatient clinic for memory disorders for their collaboration and to Marlies Karsch and Julian Rihl for their assistance in this study.

\section{References}

1 Fabrigoule C, Rouch I, Taberly A, Letenneur L, Commenges D, Mazaux JM, Orgogozo JM, Dartigues JF: Cognitive process in preclinical phase of dementia. Brain 1998;121:135-141.

2 Kratz B, Schröder J, Pantel J, Weimer D, Minnemann E, Lehr U, Sauer H: [Mild cognitive deficit in the elderly. Results of a gerontologic study] Leichte kognitive Beeinträchtigung im Alter. Ergebnisse einer gerontologischen Untersuchung. Nervenarzt 1998;69:975-982.

3 Small S, Stern Y, Tang M, Mayeux R: Selective decline in memory function among healthy elderly. Neurology 1999;52:1392-1396.

4 Celsis P: Age-related cognitive decline, mild cognitive impairment or preclinical Alzheimer's disease? Ann Med 2000;32:6-14.

5 Pearce J: The extrapyramidal disorder of Alzheimer's disease. Eur Neurol 1974;12:94-103.

6 Ellis RJ, Caligiuri M, Galasko D, Thal LJ: Extrapyramidal motor signs in clinically diagnosed Alzheimer disease. Alzheimer Dis Assoc Disord 1996;10:103-114.

7 Mölsa PK, Marttila RJ, Rinne UK: Extrapyramidal signs in Alzheimer's disease. Neurology 1984;34:1114-1116.

8 Chen JY, Stern Y, Sano M, Mayeux R: Cumulative risks of developing extrapyramidal signs, psychosis, or myoclonus in the course of Alzheimer's disease. Arch Neurol 1991;48:11411143.

9 Corey-Bloom J, Galasko D, Hofstetter CR, Jackson JE, Thal LJ: Clinical features distinguishing large cohorts with possible AD, probable AD, and mixed dementia. J Am Geriatr Soc 1993;41:31-37.

10 Funkenstein $\mathrm{HH}$, Albert MS, Cook NR, West CG, Scherr PA, Chown MJ, Pilgrim D, Evans DA: Extrapyramidal signs and other neurologic findings in clinically diagnosed Alzheimer's disease. A community-based study. Arch Neurol 1993;50:51-56.

11 Franssen EH, Kluger A, Torossian CL, Reisberg B: The neurologic syndrome of severe Alzheimer's disease. Relationship to functional decline. Arch Neurol 1993;50:1029-1039.

12 Goldman WP, Baty JD, Buckles VD, Sahrmann S, Morris JC: Motor dysfunction in mildly demented $\mathrm{AD}$ individuals without extrapyramidal signs. Neurology 1999;53:956-962.
13 Stern Y, Mayeux R, Sano M, Hauser WA, Bush $\mathrm{T}$ : Predictors of disease course in patients with probable Alzheimer's disease. Neurology 1987; 37:1649-1653.

14 Mortimer JA, Ebbitt B, Jun SP, Rinch MD: Predictors of cognitive and functional progression in patients with probable Alzheimer's disease. Neurology 1992;42:1689-1696.

15 Soininen H, Laulumaa V, Helkala EL, Hartikainen P, Reikkinen PJ: Extrapyramidal signs in Alzheimer's disease: A 3-year follow-up study. J Neural Transm Park Dis Dement Sect 1992;4:107-119.

16 Stern Y, Albert M, Brandt J, Jacobs DM, Tang MX, Marder K, Bell K, Sano M, Devanand DP, Bylsma F, Lafleche G: Utility of extrapyramidal signs and psychosis as predictors of cognitive and functional decline, nursing home admission, and death in Alzheimer's disease: Prospective analyses from the Predictors Study. Neurology 1994;44:2300-2307.

17 Chui HC, Lyness SA, Sobel E, Schneider LS: Extrapyramidal signs and psychiatric symptoms predict faster cognitive decline in Alzheimer's disease. Arch Neurol 1994;48:676678.

18 Stern Y, Jacobs DM: Preliminary findings from the predictors study: Utility of clinical signs for predicting disease course. Alzheimer Dis Assoc Disord 1995;9(suppl 1):S14-S18.

19 Lopez OL, Wisnieski SR, Becker JT, Boller F, Dekosky ST: Extrapyramidal signs in patients with probable Alzheimer disease. Arch Neurol 1997,54:969-975.

20 McKeith I, O’Brien J: Dementia with Lewy bodies. Aust NZ J Psychiatry 1999;33:800808.

21 Olichney JM, Galasko D, Salmon DP, Hofstetter CR, Hansen LA, Katzman R, Thal LJ: Cognitive decline is faster in Lewy body variant than in Alzheimer's disease. Neurology 1998; 51:351-357.

22 Hansen LA: The Lewy body variant of Alzheimer disease. J Neural Transm Suppl 1997: 5183-5193.

23 Gnanalingham KK, Byrne EJ, Thornton A, Sambrook MA, Bannister P: Motor and cognitive function in Lewy body dementia: Comparison with Alzheimer's and Parkinson's diseases. J Neurol Neurosurg Psychiatry 1997;62: 243-252.
24 Hohl U, Tiraboschi P, Hansen LA, Thal LJ, Corey-Bloom J: Diagnostic accuracy of dementia with Lewy bodies. Arch Neurol 2000;57: 347-351.

25 Lopez OL, Hamilton RL, Becker JT, Wisniewski S, Kaufer DI, DeKosky ST: Severity of cognitive impairment and the clinical diagnosis of AD with Lewy bodies. Neurology 2000; 54:1780-1787.

26 Lopez OL, Wisniewski S, Hamilton RL, Becker JT, Kaufer DI, DeKosky ST: Predictors of progression in patients with AD and Lewy bodies. Neurology 2000;54:1774-1779.

27 Walker Z, Allen RL, Shergill S, Katona CL: Neuropsychological performance in Lewy body dementia and Alzheimer's disease. Br J Psychiatry 1997;170:156-158.

28 Gainotti G, Marra C, Villa G, Parlato V, Chiarotti F: Sensitivity and specificity of some neuropsychological markers of Alzheimer dementia. Alzheimer Dis Assoc Disord 1998;12:152162.

29 Kischka U, Mandir AS, Ghika J, Growdon JH: Electrophysiologic detection of extrapyramidal motor signs in Alzheimer's disease. Neurology 1993;43:500-505.

30 Caligiuri MP, Lohr JB, Panton D, Harris MJ: Extrapyramidal motor abnormalities associated with late-life psychosis. Schizophr Bull 1993;19:747-754.

31 Kluger A, Gianutsos JG, Golomb J, Ferris SH, George AE, Franssen E, Reisberg B: Patterns of motor impairment in normal aging, mild cognitive decline, and early Alzheimer's disease. J Gerontol B Psychol Sci Soc Sci 1997;52:2839.

32 Bellgrove MA, Phillips JG, Bradshaw JL, Hall KA, Presnell I, Hecht H: Response programming in dementia of the Alzheimer type: A kinematic analysis. Neuropsychologia 1997,35: 229-240.

33 Caselli RJ, Stelmach GE, Caviness JN, Timmann D, Royer T, Boeve BF, Parisi JE: A kinematic study of progressive apraxia with and without dementia. Mov Disord 1999;14:276287.

34 Slavin MJ, Phillips JG, Bradshaw JL, Hall KA, Presnell I: Consistency of handwriting movements in dementia of the Alzheimer's type: A comparison with Huntington's and Parkinson's diseases. J Int Neuropsychol Soc 1999;5: 20-25. 
35 Caligiuri MP, Peavy G: An instrumental study of the relationship between extrapyramidal signs and psychosis in Alzheimer's disease. J Neuropsychiatry Clin Neurosci 2000;12:3439.

36 Richards M, Marder K, Bell K, Dooneief G, Mayeux R, Stern Y: Interrater reliability of extrapyramidal signs in a group assessed for dementia. Arch Neurol 1991;48:1147-1149.

37 Marquardt C, Mai N: A computational procedure for movement analysis in handwriting. $\mathrm{J}$ Neurosci Methods 1994;52:39-45.

38 Jahn T, Cohen R, Mai N, Ehrensperger M, Marquardt C, Nitsche N, Schrader S: Assessment of fine and gross motor dysdiadochokinesia in schizophrenic patients: Development of methods and first results of a computer-based microanalysis. Z Klin Psychol 1995;24:300315.

39 Tigges P, Mergl R, Frodl T, Meisenzahl EM, Gallinat J, Schröter A, Riedel M, Müller N, Möller H-J, Hegerl U: Digitized analysis of abnormal hand-motor performance in schizophrenic patients. Schizophr Res 2000;45:133143.

40 Mavrogiorgou P, Mergl R, Tigges P, El Husseini J, Schröter A, Juckel G, Zaudig M, Heger $\mathrm{U}$ : Kinematic analysis of handwriting movements in patients with obsessive-compulsive disorder. J Neurol Neurosurg Psychiatry 2001; 70:605-612.

41 Eichhorn TE, Gasser T, Mai N, Marquardt C, Arnold G, Schwarz J, Oertel WH: Computational analysis of open loop handwriting movements in Parkinson's disease: A rapid method to detect dopamimetic effects. Mov Disord 1996;11:289-297.

42 Siebner HR, Ceballos-Baumann A, Standhardt H, Auer C, Conrad B, Alesch F: Changes in handwriting resulting from bilateral high-frequency stimulation of the subthalamic nucleus in Parkinson's disease. Mov Disord 1999;14: 964-971.

43 Phillips JG, Bradshaw JL, Chiu E, Bradshaw JA: Characteristics of handwriting of patients with Huntington's disease. Mov Disord 1994; 9:521-530.

44 Sachdev P, Aniss AM: Slowness of movement in melancholic depression. Biol Psychiatry 1994;35:253-262.

45 Lafer B, Renshaw PF, Sachs GS: Major depression and the basal ganglia. Psychiatr Clin North Am 1997;20:885-896.

46 Sabbe B, Hulstijn W, van Hoof J, Zitman F: Fine motor retardation and depression. J Psychiatr Res 1996;30:295-306.
47 McKhann G, Drachman D, Folstein M, Katzman R, Price D, Stadland EM: Clinical diagnosis of Alzheimer's disease: Report of the NINCDS-ADRDA work group under the auspices of Department of Health and Human Services Task Force on Alzheimer's disease. Neurology 1984;11:939-944.

48 Petersen RC, Smith GE, Waring SC, Ivnik RJ, Tangalos EG, Kokmen E: Mild cognitive impairment: Clinical characterization and outcome. Arch Neurol 1999;56:303-308.

49 American Psychiatric Association: Diagnostic and statistical manual of mental disorders, ed 4. Washington, APA, 1994

50 Folstein M, Folstein S, McHugh PR: Mini Mental State: A practical method for grading the cognitive state of patients for clinicians. J Psychiatr Res 1975;12:189-198.

51 Caligiuri MP, Rockwell E, Jeste DV: Extrapyramidal side effects in patients with Alzheimer's disease treated with low-dose neuroleptic medication. Am J Geriatr Psychiatry 1998;6: 75-82.

52 Devanand DP, Marder K, Michaels KS, Sackeim HA, Bell K, Sullivan MA, Cooper TB, Pelton GH, Mayeux R: A randomized, placebocontrolled dose-comparison trial of haloperidol for psychosis and disruptive behaviors in Alzheimer's disease. Am J Psychiatry 1998;155: 1512-1520.

53 Oldfield RC: The assessment and analysis of handedness: The Edinburgh Inventory. Neuropsychologia 1971;9:97-113.

54 Marquardt C, Mai N: CS - Computergestützte Analyse der Bewegungsabläufe beim Schreiben. Bedienungshandbuch. München, MedCom, 1992.

55 Lane RM: SSRI-induced extrapyramidal sideeffects and akathisia: Implications for treatment. J Psychopharmacol 1998;12:192-214.

56 Hegerl U, Möller H-J: Pharmakotherapie der Altersdepression. Nervenarzt 2000;71:1-8.

57 Carcenac D, Martin HC, Kiesmann M, Demuynck RC, Alt M, Kuntzmann F: Extrapyramidal syndrome in three Alzheimer patients given donepezil. Presse Med 2000;29:992993.

58 Box GEP: Some theorems on quadratic forms applied in the study of analysis of variance problems. 1. Effects of inequality of variance in the one-way classification. Ann Math Stat 1954;25:290-302.

59 Morgan M, Bradshaw JL, Phillips JG, Mattingley JB, Iansek R, Bradshaw JA: Effects of hand and age upon abductive and adductive movements: A kinematic analysis. Brain Cogn 1994;25:194-206.
60 Bellgrove MA, Phillips JG, Bradshaw JL, Gallucci RM: Response (re)programming in aging: A kinematic analysis. J Gerontol A Biol Sci Med Sci 1998;53:M222-M227.

61 Mergl R, Tigges P, Schröter A, Möller H-J, Hegerl U: Digitized analysis of handwriting and drawing movements in healthy subjects: Methods, results and perspectives. J Neurosci Methods 1999;90:157-169.

62 Hollerbach JM: An oscillation theory of handwriting. Biol Cybern 1981;39:139-156.

63 Van Galen GP, Stelmach GE: Handwriting Issues of psychomotor control and cognitive models. Acta Psychol 1993;82.

64 Ballard C, Bannister C, Solis M, Oyebode F, Wilcock G: The prevalence, associations and symptoms of depression amongst dementia sufferers. J Affect Disord 1996;36:135-144.

65 Raskind MA: The clinical interface of depression and dementia. J Clin Psychiatry 1998; 59(suppl 10):9-12.

66 Fichter MM, Bruce ML, Schroppel H, Meller I, Merikangas K: Cognitive impairment and depression in the oldest old in a German and in US communities. Eur Arch Psychiatry Clin Neurosci 1995;245:319-325.

67 Schröder J, Kratz B, Pantel J, Minnemann E, Lehr U, Sauer H: Prevalence of mild cognitive impairment in an elderly community sample. $\mathrm{J}$ Neural Transm Suppl 1998;54:51-59.

68 Steffens DC, Hays JC, Krishnan KR: Disability in geriatric depression. Am J Geriatr Psychiatry 1999; 7:34-40.

69 Christensen H, Griffiths K, Mackinnon A, Jacomb P: A quantitative review of cognitive deficits in depression and Alzheimer-type dementia. J Int Neuropsychol Soc 1997;3:631651.

70 Wolf H, Grunwald M, Ecke GM, Zedlick D, Bettin S, Dannenberg C, Dietrich J, Eschrich $\mathrm{K}$, Arendt T, Gertz HJ: The prognosis of mild cognitive impairment in the elderly. J Neural Transm Suppl 1998;54:31-50.

71 Petersen RC: Mild cognitive impairment: Transition between aging and Alzheimer's disease. Neurologia 2000;15:93-101.

72 Small BJ, Fratiglioni L, Viitanen M, Winblad B, Backman L: The course of cognitive impairment in preclinical Alzheimer disease: 3- and 6-year follow-up of a population-based sample. Arch Neurol 2000;57:839-844.

73 Devanand DP, Sano M, Tang MX, Taylor S, Gurland BJ, Wilder D, Stern Y, Mayeux R: Depressed mood and the incidence of Alzheimer's disease in the elderly living in the community. Arch Gen Psychiatry 1996;53:175-182. 